\title{
La Hipótesis Revolucionaria. Nacionalismo Vasco y la Crítica a la Modernidad ${ }^{1}$
}

\section{The Revolutionary Hypothesis. Basque Nationalism and the Critique of Modernity}

\author{
Adrián Almeida Díez ${ }^{2}$ \\ Universidad del País Vasco (España)
}

Recibido: 29-12-18

Aprobado: 17-11-19

\section{Resumen}

El presente trabajo trata de aportar una reflexión sobre los orígenes y evoluciones del nacionalismo vasco en atención a su rechazo a la modernidad, comprendiendo reflexivamente este rechazo en relación a las críticas a la modernidad realizadas por la primera generación de la Escuela de Frankfurt (especialmente por los autores Max Horkheimer y Theodor Adorno) y considerando la posibilidad, y en virtud de lo anterior, de replantear la reactancia del nacionalismo vasco no en un sentido reaccionario, sino con un significado revolucionario. Se analizará el primer nacionalismo vasco fundado por Sabino Arana en el siglo XIX y el surgido a partir de la organización ETA, la izquierda abertzale, durante los años 60 .

Palabras-clave: modernidad, nacionalismo vasco, Escuela de Frankfurt, ETA.

\footnotetext{
${ }^{1}$ Este texto se ha financiado a través del programa para la Formación del Profesorado Universitario (Referencia: FPU17/00816) y se enmarca dentro del grupo de investigación HAR2015-64920-P

22(adrian.almeida@ehu.eus) Investigador predoctoral por la Universidad del País Vasco/ Euskal Herriko Unibertsitatea, en el grupo de investigación El Nacionalismo Vasco en Perspectiva Comparada. Se graduó en Humanidades con mención en Historia en la Universidad Deusto con Premio Fin de Carrera por esta titulación. Realizó además el Máster en Historia Contemporánea por la Universidad Autónoma de Madrid y llevó a cabo prácticas de archivo en el Archivo del Nacionalismo Vasco en Bilbao.

ORCID: https://orcid.org/0000-0002-2552-9766.
} 


\begin{abstract}
This article wants to offer a new reflexion about the origins and the historical evolution of the Basque Nationalism. According to the critical perspectives to modernity which the first generation of the Frankfurt School made (specially, the philosophers Max Horkheimer and Theodor Adorno), we are going to analyze the reactance of the Basque Nationalism to modernity considering this as a core of a revolutionary significance. It is going to be examined the first Basque Nationalism created by Sabino Arana in 19th Century, and the new Basque Nationalism ideology emerged in sixties after the creation of the group ETA, commonly named: patriotic left.
\end{abstract}

Key-words: Modernity, Basque Nationalism, Frankfurt School, ETA.

\title{
Introducción
}

A la luz de las críticas a la modernidad que hicieran los filósofos de la Escuela de Frankfurt, este artículo tiene como objetivo replantear los orígenes y desarrollos del nacionalismo vasco como reacciones de freno -en expresión benjaminiana- ante la aceleración moderna. En tal sentido, busca reflexionar sobre el rechazo a la modernidad del nacionalismo vasco, entendiendo a este último, y en su propia evolución histórica, como engendrador de un sustrato revolucionario antisistémico.

Desde la Escuela referida, y más concretamente desde la óptica de dos de sus grandes nombres y fundadores, Max Horkheimer y Theodor Adorno (sin olvidar la importancia de Walter Benjamin), la Ilustración, en su afán por desencantar el mundo, acabó por elevar un tipo de razón que, lejos de lograr la emancipación del hombre, lo habría condenado a él mismo. El triunfo de la razón habría sido en realidad la glorificación de una razón instrumental traducida en su evolución histórica no sólo en el dominio sobre la cosas, sino en la cosificación de la propia subjetividad. El triunfo de la razón instrumental condenaría sistemáticamente todas aquellas prácticas sociales que no pudieran deducirse desde la lógica de la practicidad. Las expresiones culturales comunitarias tradicionales, en la fundamentación político-económica del Estado nación moderno, serían así desprovistas de sentido y conceptualizadas como arcaicas o irracionales (Jaúregui 1998: 22-23). Desde este punto de vista, por tanto, la reactancia a la extensificación de la razón instrumental, como fundamentación del alcance de la modernidad, queda netamente resignificada: desde la perspectiva reaccionaria o barbárica pasaría a considerarse una fundamentación para la hipótesis revolucionaria. 
El rechazo de lo que no cabe en la nueva y moderna sociedad histórica simplificada, se convierte en el núcleo de una "fuerza que rebasa, la fuerza que contradice toda identificación, la fuerza que desborda" y capacita la formulación de un nosotros irreductible (Holloway S.f). El nacimiento del nacionalismo vasco puede considerarse así como un rechazo. Una respuesta, romántica, "a ese tremendo e incontrolable impacto social de los nuevos tiempos" (Luengo Texeidor 2009: 144). Pero, ¿qué cabría decir del nuevo nacionalismo surgido a partir de ETA? No son pocos los autores que han tratado de ver en este nuevo nacionalismo, y en relación al rechazo a la modernidad, una vuelta al sabinismo amoldado a los tiempos (Gaizka Fernández o José Luis de la Granja) o una confluencia de los milenarismos nacionalista y comunistas, que lejos de contentarse en ser una fase provisional de negación de la sociedad, aspirarían a afirmarse institucionalmente y, con ello, a convertirse en un proyecto totalitario (Aranzadi 1981:119). Lo que en este trabajo se plantea, entroncando en parte con la segunda de las posturas, es que a través de ETA se conceptualiza la apertura hacia nueva subjetividad revolucionaria denominada Pueblo Trabajador Vasco, que se fundamenta en una dialéctica de la no-identidad doble territorializada en el País Vasco bajo la dictadura de Franco; enclave donde se produce un rechazo a la totalidad como totalidad antagónica o un rechazo al "aplastamiento de lo no idéntico por la identidad" (Nahuel Martín 2016: 187210). En otro sentido, ETA recogería conceptualmente el Gran Rechazo -por emplear la categoría marcusiana- a la integración total de la diferencia buscada por el franquismo; la difuminación de la diferencia clasista y su potencial confrontación, y el propio reduccionismo de la diferencia cultural del Estado (Lefebvre,1972). Tal nucleización del Gran Rechazo por ETA, transformaría al originario nacionalismo vasco en una hipótesis revolucionaria que, lejos de pretender el retraimiento romántico de la historia, plantearía una dialéctica a la integración sistémica de la modernidad.

\section{La Dialéctica de la Ilustración (DI)}

La DI es una obra capital para entender el alcance la crítica filosófica de la escuela de Frankfurt a las vicisitudes de las sociedades avanzadas. Como señaló Albrecht Wellmer, la DI trata de hacer confluir dos tradiciones filosóficas dispares. Por un lado, aquella que desde Schopenhauer pasando por Nietzsche llega hasta Klages. Por otra, aquella que derivando de Hegel, parando en Marx y Weber, llega hasta Lukács (Wellmer 1993: 15-18). Desde estos puntos de vista, la DI se constituye como un alegato crítico contra el establecimiento a partir del triunfo de la Ilustración de un modelo de razón instrumental. 
La Ilustración se había propuesto en origen la necesidad de explicar el mundo desde un punto de vista racional frente a proyecciones explicativas de carácter mítico. El predominio de la razón haría emancipar al hombre de las cadenas del mito y de la religión, poniéndolo en las vías del tren del progreso. Con la Ilustración "el hombre se reconoce a sí mismo en los dioses, que pasan a ser vistos como productos febriles de su imaginación temerosa, y el temor a lo divino como pesadilla de la que esa Ilustración, como ciencia verdadera, nos libra" (Hernández Pacheco 1996: 70).

En recogimiento de la tesis de Weber en torno a la modernidad y asumiendo la teoría de la reificación lukasiana, Horkheimer y Adorno considerarán que, pese a la originaria pretensión emancipadora, la Ilustración ha dado como resultado la extensión de una razón instrumental cuya función no es la liberación mediante el conocimiento, sino el dominio de la naturaleza (Ibidem:71). La prevalencia de ese tipo de Logos y su expansión alcanzaría, ya en su propio origen, al sujeto. En tal medida, se produce un intento por dominar al sujeto y reprimir su propia naturaleza, convirtiendo a éste en una cosa. Se formula así el principio de cosificación del sujeto expresado en este evocador texto: "con la cosificación del espíritu fueron hechizadas las mismas relaciones entre los hombres (...). El animismo había vivificado la cosa; el individualismo tardío cosifica las almas”(Horkheimery Adorno 2016:43). Así pues,

\begin{abstract}
“el en sí-mismo, que tras la metódica eliminación de todo vestigio natural como mitológico no debía ya ser cuerpo ni sangre ni alma, ni tan siquiera yo natural, constituyó, sublimado en sujeto trascendental o lógico, el punto de referencia de la razón, de la instancia legisladora del obrar. Quien confía en la vida directamente, sin relación racional con la autoconservación, vuelve, según el juicio tanto de la ilustración como del protestantismo, a la prehistoria" (Ibidem:44).
\end{abstract}

La reificación del sujeto consiste, por tanto "en la transformación de las propiedades, relaciones y acciones humanas en propiedades, relaciones y acciones de cosas" (Cortina 2008:81). El hombre, en la pretensión de dominar la naturaleza, acaba por dominar su propia naturaleza; a sí mismo, condenando como irracional todos aquellos impulsos o pensamientos míticos. La vida queda reducida a las exigencias de la autoconservación, en la cual la razón actúa como instrumento meramente funcionalista. Este es el tipo de razón-como se indica en la DI-que guiará a Ulises en su viaje;

\footnotetext{
"el héroe griego, que utiliza su astucia solo para beneficio personal (...) en lugar de emanciparse de las arbitrariedades de las deidades griegas, sólo hace uso de su capacidad intelectual para someter a mujeres, naturaleza y pueblos primitivos"(Zelik 2017:48).
} 
La Ilustración se concibe así no como progreso, sino como el inicio del dominio y la barbarie. La historia que se derivaría del triunfo de la Ilustración y de la asunción del poder burgués se describe como una evolución que no podría denominarse emancipadora, sino de retraimiento general del sujeto. El fascismo consecuentemente es interpretado en la DI como secuencia lógica del pecado originario de la Ilustración y no como disrupción. En este sentido, el fascismo se concibe como una renuncia explícita a los ideales existentes en la Ilustración una vez la burguesía se hubo implantado como clase dominante. Bajo el fascismo se mantendría el orden de la modernidad capitalista como extensión tajante de la razón instrumental, al tiempo que los ideales y excedentes utópicos de la Ilustración, se convertían en un despojo que sólo podía beneficiar, en su llamada a la libertad, a la revolución contra el dominio. Y de esta forma,

\begin{abstract}
"todos los vínculos tradicionales cayeron (...) bajo el veredicto que los presentaba como meros tabúes, incluidos aquellos que eran necesarios para la existencia del propio orden burgués. El instrumento con el que la burguesía había llegado al poder: liberación de fuerzas, libertad general, autodeterminación, en suma, Ilustración, se volvió contra la burguesía tan pronto como ésta, convertida en sistema de dominio, se vio obligada a ejercer la represión" (Horkheimer y Adorno 2016: 105).
\end{abstract}

La Ilustración, que habría pasado por un período liberal antes de la llegada al poder de la burguesía, se encarnaba ahora tan sólo "como terror arcaico en la forma racionalizada del fascismo", lo cual significaba que sus ideales racionalistas quedaban en exclusiva fijados en el funcionamiento de un modelo económico que recordaba permanente quiénes resultaban los herederos triunfantes de todo el proceso (Ibidem:99). La Ilustración, lejos del sapere aude kantiano que invitaba al hombre a pensar y a fijar sus contenidos morales en el imperativo categórico, se revelaba como el inicio de un proceso en el que el fin de la autoconservación sustituía enteramente el pensamiento. El fascismo,

\begin{abstract}
"en contra del imperativo categórico y en tanto más profunda concordancia con la razón pura, trata a los hombre como cosas, como centros de modos de comportamiento. Contra el océano de la violencia abierta que ha irrumpido realmente en Europa, los amos habían querido proteger al mundo burgués sólo mientras la concentración económica no estuviera suficientemente avanzada (...) el orden totalitario pone al pensamiento calculador en posesión de todos sus derechos y se atiene a la ciencia en cuanto tal. Su canon es su propia capacidad productiva" (Ibidem:98).
\end{abstract}

Así, con el fascismo, se llegaría a un punto culminante de un ciclo histórico iniciado en la Ilustración, que proponiéndose el domino del hombre de la 
propia naturaleza, se resuelve como "la historia del dominio del hombre por el hombre" (Horkheimer 2010). El domino de la naturaleza del sujeto, la presión que sobre ella ejerce la razón instrumental es, por otra parte, aprovechada por el fascismo para articular a las masas en torno a una presunta liberación de la naturaleza.

\section{Anti-modernidad y primer nacionalismo vasco}

A la luz de esta interpretación de Horkheimer y Adorno, se puede observar el nacimiento del nacionalismo vasco desde una perspectiva que ve a éste como un fenómeno social, que si bien se ha catalogado generalmente de reaccionario, podría ser articulador en sus entrañas de una fuerza revolucionaria contra las nuevas relaciones sociales derivadas de la modernidad. Su fuerza residirá así en ser una proyección de orden social alternativa a la evolución histórica impuesta desde el poder del Estado y, por tanto en concebirse, ya en sus inicios, como un movimiento social anti-sistema (Mees 1991:21). Como un rechazo a la aplicación práctica del reduccionismo abstractivo de la realidad social y, por tanto, como desvelamiento "de la no-identidad, de lo que no cabe" (Holloway S.f).

Los orígenes del nacionalismo vasco se derivan de la abolición de los fueros vascos en 1876. Con aquel acto, las provincias vascas cambiaron radicalmente su relación con un Estado español que avanzaba progresivamente hacia la uniformidad en un sentido político ${ }^{3}$. La inmediata consecuencia de este hecho, y como resultado de la pérdida de la segunda de las guerras carlistas frente al liberalismo alfonsino, es la intrusión de un modelo de Concierto Económico que permite la rápida progresión de un capitalismo industrial fundamentalmente en el entorno de Bizkaia y el Gran Bilbao.

Los levantamientos carlistas son tradicionalmente caracterizados como reacciones al sentido liberalizante emanado desde las instancias del poder del Estado. Un sentido liberalizante que tempranamente es visto, en este territorio, como disruptivo de los parámetros existenciales devenidos de un orden que configura un marco específico de relaciones políticas y económicas. A decir de Alfonso Pérez Agote,

"las guerras carlistas se pueden ver como un conflicto entre el progresismo
liberal y las tendencias conservadoras, entre modernidad y tradición,
entre ciudad y campo. Pero todo esto (...) proviene de la localización del
conflicto y también de que el propio conflicto se plantea como un conflicto
por la localidad: tendencia unitaria española, contra tendencia localista. Las

${ }^{3}$ A principios del siglo XIX, y a decir de Xosé M. Núñez-Seixas, "España no era un Estado plurinacional, pero sí una comunidad política imperial y pluriétnica” (Núñez-Seixas 2018).

Araucaria. Revista Iberoamericana de Filosofia, Politica, Humanidades y Relaciones Internacionales, año $22, \mathrm{n}^{\circ} 43$. Primer semestre de 2020. Pp. 119-142. ISSN 1575-6823 e-ISSN 2340-2199 https://dx.doi.org/10.12795/araucaria.2020.i43.06 
condiciones económicas y sociales del campesino vasco eran específicas, y lo que se representaba como progreso y reforma social en otros lugares, no se representaba así en el País Vasco" (Pérez Agote 2008:84).

La derrota en esta última guerra y la sucesiva abolición foral constataron así el nacimiento del mundo moderno sobre el territorio vasco peninsular y de forma paralela la destrucción del entramado institucional que daba garantía de continuidad a una forma particular de vida en estos territorios (Solozabal 1975: $205)^{4}$. De forma concreta, se inicia la emergencia de una nueva clase burguesa que se impone, liberada al fin de las trabas institucionales que consagraban a los jauntxos como clase dominante pre-capitalista, su dinamismo en la explotación de las riquezas del territorio (Corcuera 1980:59). Surge en paralelo, en estos territorios, un sentimiento de defensa que llega incluso a ciertos sectores liberales del país que habiéndose encontrado luchando frente al carlismo, por lo que el carlismo representaba de ultraconservador, se topaban de golpe con la destrucción de una ley que particularizaba el regir interno de la sociedad y la específica unión del territorio con el conjunto del Estado.

Entre 1808 y 1868, estos liberales vascos, que constituían un grupo francamente minoritario, habían sido proclives a conservar los rasgos tradicionales asociados al territorio, introduciendo si acaso adaptaciones propias al período (Rubio, 1996: 383). La progresiva captación y patrimonialización de la defensa del orden foral por parte de los carlistas y su proyecto político, finalmente "acabó haciendo mella en la conciencia liberal" (Molina 2005:145). Tras la última intentona carlista, desde las instancias estatales se produjo, como señalaba Corcuera, "la identificación entre vascos y carlistas (...): la derrota carlista habría de suponer el fin del privilegio de no dar al Estado ni soldados, ni dinero. El fin del sistema foral de las provincias vascas..." (Corcuera 1980:82). La guerra carlista indujo, en paralelo, a proyectar, desde estos entornos estatales, un tipo de exaltación patriótica española que enmarcaba el fin de los fueros como acto consustancial para la regeneración de la nación. Los vascos, adalides fundamentales del poder carlista, se representaban como gentes barbáricas, eran los portadores de una enfermedad política llamada carlismo, la cual se incubaba en el Fuero (Castells 2009: 109; Molina 2005: 149-151).

Históricamente, la defensa de la foralidad, captada por el carlismo a partir de 1868 (Elorza 1978: 14), marca así el primer punto de una concepción anti-moderna que habría de desembocar en el nacionalismo aranista. A este

\footnotetext{
${ }^{4}$ Para la sociedad campesina y artesana, ha señalado Fernando Molina, "los fueros representaban (...) un conjunto de ventajas tangibles y concretas de naturaleza económica, fiscal y militar". Eran la ley del caserío frente a la moderna ley de la ciudad. Para las clases dirigentes, los fueros "significaban un imaginario romántico y ruralista de identidad que legitimaba una situación de privilegio político y económico" (Molina 2005: 137-138). Los fueros resultaban, compatiblemente con lo anterior, "un canal de transmisión tanto de una identidad nacional, la española, como, a la vez, de otra étnoregional, la vasca" (Castells 2007:117).
}

Araucaria. Revista Iberoamericana de Filosofia, Política, Humanidades y Relaciones Internacionales, año $22, \mathrm{n}^{\circ} 43$. Primer semestre de 2020. Pp. 119-142. ISSN 1575-6823 e-ISSN 2340-2199 https://dx.doi.org/10.12795/araucaria.2020.i43.06 
respecto, Javier Fernández Sebastián señaló que el fuerismo (y el propio carlismo) representó una contestación esencialmente contra el primero de los dos puntales establecidos por Max Weber como núcleos de la modernidad; estos puntales eran la formación de un aparato estatal burocrático y la empresa capitalista. Así pues, esta primera oleada de resistencia se enmarcaría como lucha frente al sentido centralizador institucional y uniformización del Estado. Una pretensión, la de la uniformización institucional, que se inició con y contra la invasión napoleónica de los territorios de la monarquía española (Fernández Sebastián 1993:36). El fuerismo habría de interpretarse así como una reacción romántica al intento moderno construcción de la nación política española.

El fuerismo, antes de la abolición foral definitiva de 1876, se había encarnado a través de autores como el músico Jesús María Iparraguirre o el político Novia Salcedo, el cual y en su obra de 1851, Defesa histórica, legislativa y económica del Señorío de Vizcaya y provincias de Álava y Guipúzcoa, señalaba en un sentido burkeano (Fernández Sebastián 1990: 61-88):

\footnotetext{
"Para llevar adelante entonces el mal ideado proyecto [de la revolución moderna], se hace preciso remover cuantos obstáculos lo embarazan, desfigurar la historia en que se funda el principio, progresos y derechos de los pueblos, desquiciar la legislación más reconocida, atropellar las costumbres, condenar sin exámenes los más anticuados usos..." (Novia Salcedo 1851:11).
}

De forma paralela, y tras la ley abolitoria de 1876, hacen confluencia con la defensa pro fueros diversas corrientes literarias que destacan por fijar una imagen rural y romántica del territorio (Elorza 1977: 355-376). Entre estos autores influyentes podrían destacarse Antonio Trueba o Fermín Caballero (dentro de la literatura ruralista) y Joseph Agustín Chaho (dentro del romanticismo). La defensa de la tradición foral vendrá igualmente atravesada por posturas integristas a través de las cuales se fundamenta un axioma recogido por Arana; en la medida en que el liberalismo es antirreligioso, éste es antivasco, pues la ley foral es el puntal de un orden de tradición cuya existencia es sustentada en la misticidad religiosa (dentro de estas corrientes religiosas podría destacarse a Arístides de Artiñano). La emanación de un orden burocrático, racional y desencantador (dominador de la naturaleza), serían confabulaciones que, atacando la base de la legitimidad del orden establecido (la tradición), buscarían, desde fuera (sin ser una evolución oriunda en ese sentido modernizante ni un pacto con las fuerzas liberales) y a través de las armas, disolver el propio orden indígena. El hecho de que la construcción de la nación española fuera sustentada en el adalid de un liberalismo "débil y territorialmente fraccionado", el cual impondría su modelo de Estado no sobre ciertos elementos de participación y conversión ciudadana, sino sobre una imposición aplastante (Mees 1996: 6783), haría caracterizar consecuentemente la muerte de la tradición, y entre parte 
de la sociedad vasca, no como un reverso de la emergencia, positiva, de ciertos elementos progresistas y liberadores asociados a la propia imposición ilustrada, sino como la muerte de la libertad originaria misma. La contemporaneidad como igualdad entre los hombres, como democracia, se concebía como un retroceso, como imposición de una perspectiva que era ya recogida en la tradición (Jauréguiberry 2007:23). Así pues, en parte de la nueva hornada de fueristas, muchos de ellos claramente liberales, destaca una imagen idealizada del país, pero sobre todo un sentimiento de pérdida del carácter propio que jurídica e identitariamente definía al País de los Vascos.

Unido a este sentimiento, comienza a germinar una demanda por la defensa de la cultura propia que en el desarrollo de la modernidad española tenía visos de desaparecer. Solozabal destacó que el sentido de rechazo antimoderno vasco no guarda sólo una relación directa con "la quiebra del régimen foral". Ésta sólo fue una respuesta más de rechazo al "proceso de modernización español", el cual amenazaba con llevarse por delante los rasgos culturales propios como el euskera o el folklore tradicional (Solozabal 1975:308). A este respecto conviene añadir, siguiendo el punto de vista de Ernest Gellner, que la emergencia del capitalismo industrial supone también la formación de un proletariado que, inmigrado de sus núcleos culturales originarios, trata en el territorio de llegada de fundamentar en el idioma un foco para su cohesión comunitaria (Smith 2000:67). En el ámbito vasco, este fenómeno tuvo lugar cuando amplias masas de inmigrantes se instalaron en los entornos ampliamente industrializados, provocando la alarma entre los oriundos. La defensa de la cultura propia, que puede comprenderse, como recogió Ludger Mees del historiador Miroslav Hroch, como la primera fase para la formación de un movimiento nacional (Mees 1991:20), se inicia en estos momentos desde los núcleos de la intelligentsia foralista. Se fundan así agrupaciones como la Sociedad Euskara en Navarra o la Sociedad Euskal Herria en Bilbao.

Las élites industriales vascas en ciernes, por su parte, trasplantarían rápidamente su lealtad de la defensa de la tradición foral a un sistema de Concierto Económico y a unas Diputaciones (en sustitución de las Juntas) que les resultaban del todo más ventajosas para su definitiva prosperidad como rectores de la vida pública (a nivel político y económico) (Díez Medrano 1999:87). El liberalismo defensor de los fueros, su intelligentsia, encarnada de manera más prominente por la figura del foralista intransigente, Fidel de Sagarminaga -fundador de la Sociedad Euskal Herria y del partido político Unión Vasco Navarra- se vaciaba de sus posibles patrocinios capitalistas (con la destacada excepción del naviero Ramón de la Sota), los cuales fijaron mayoritariamente sus proyecciones políticas para el territorio en los partidos de ámbito estatal. 
De esta forma, la industrialización, capacitada por la abolición de la "ley vieja", acabará por desleír el Weltanschauung tradicional del territorio y de su población, así como a las élites liberales defensoras del estatus quo foral. Solozabal se preguntaba: “¿En virtud de qué ha tenido lugar el paso de la conciencia étnico cultural a la política? En virtud de la industrialización. La obra de Arana es una protesta contra la industrialización, contra sus efectos y sus agentes" (Solozabal 1975:326). Para Ander Gurrutxaga,

“el nacionalismo, en sus orígenes, es la expresión de grupos tradicionales autóctonos ante lo que perciben es la quiebra de su sistema tradicional de vida. Su respuesta es la expresión comunitaria del discurso social, político, simbólico que dota de sentido a esos grupos y crea una idea de sociedad comunitaria" (Gurrutxaga 2002: 26-27) .

En la misma línea, Ludger Mees ha indicado que: "it was the process of accelerated socioeconomic modernization that gave the decisive impulse to this change from ethnic to national identity" (Mees 2018: 462-489).

La emergencia de la modernidad entendida como la construcción de la España Estado-nación se contrapondría así a la pervivencia y evolución autóctona de los rasgos culturales, del orden jurídico y de sus clases directoras que, paralelamente, se convierten en lo que Walter Benjamin denominó "montones de ruinas".

El pensamiento del primer Sabino Arana, y del primer nacionalismo, se encuentra así dirigido esencialmente con una impronta anti-maketa; anti obrero industrial inmigrante. Como elemento-consecuente de la causa-industrial capitalista. Y así, y tomando una interpretación de Žižek, ¿no es este racismo una forma primitiva del anticapitalismo? El esloveno se hubo preguntado: “ ¿No se basaba acaso [la proyección nazista] en la nostalgia utópica de la auténtica vida comunitaria, en el rechazo plenamente justificable de la irracionalidad de la explotación capitalista?" (Žižek 2008:20). Como se ha dicho, que el nazismo se aprovechara de esos anhelos existenciales -legítimos por cuanto se revelaban contra la irracional racionalidad del dominio capitalista-no legitima el racismo a partir del cual el nazismo pretendió, para salvar al propio sistema capitalista, canalizar el desborde social, el rechazo a la modernidad. Recordaba Horkheimer que

\footnotetext{
"los nazis manipularon los deseos reprimidos del pueblo alemán. Cuando los nazis y los industriales y militares que estaban detrás de ellos lanzaron su movimiento, tuvieron que ganarse a las masas, unas masas cuyos intereses materiales no eran los suyos (...). Los impulsos naturales reprimidos fueron puestos al servicio de las necesidades del racionalismo nazi" (Horkheimer 2010:137-138).
}

${ }^{5}$ Como ha indicado José María Portillo, a partir de la obra de Sabino Arana Bizkaya por su independencia, el nacionalismo vasco hasta la actualidad entiende que el régimen foral "es la soberanía originaria" (Portillo 2018:84). 
Arana equivocaba el foco del rechazo, asumiendo la necesidad del retraimiento de la historia, retornar a la supuesta autenticidad, y lo hacía atrapado a medio camino entre dos clases sociales en lucha: los grandes capitalistas y los obreros inmigrantes. Los primeros componían, desde la perspectiva nacionalista, una clase social no tanto enemiga del país -eran, en su mayor parte, étnicamente vascos- sino esencialmente competidora de las clases medias desplazadas. Los segundos, víctimas absolutas de todo el proceso, son observados como los demonios de la industrialización, "culpables de su propia pobreza e incultura y responsables de la introducción en la arcádica Euskal Herria no sólo de malas costumbres sino de las más (...) perniciosas ideas". (Corcuera 1980: 582-581).

Inevitablemente la alegoría que del mundo rural haría el nacionalismo, como núcleo de la cultura propia y del regir social armónico, puede observarse como una resistencia frente a un deseo de progreso que es no ya sólo interpretado como ajeno a la voluntad de los oriundos, sino como introductor de un modelo de racionalidad instrumental que no concibe la permanencia en el territorio de elementos culturales ajenos a aquellos que se consideran prácticos en el desarrollo de un capitalismo industrial fuerte y una nación unitaria. En 1899, Arana escribía un artículo en donde ponía en cuestión ese afán pretendidamente civilizatorio de la nueva sociedad emergente:

"los vascos aquellos de costumbres morigeradas y de proverbial hombría de bien eran unos ignorantes, estaban sin civilizar; en cambio, los que hoy viven en continuo roce con el extraño, los que usan navaja, los que blasfeman, los que cantan flamenco, ésos están civilizados" (Arana 1999: 326).

\section{Señalaba en otra ocasión:}

"la sonrisa del pasado se ha trocado en lamento para nosotros ¿Qué hemos hecho de nuestra tierra? ¿Qué hacemos de nuestro cerebro? En vez de hombres de nuestro país y de nuestro tiempo, con avance determinado por una cadena de hechos anteriores, somos luz reflejada, copia, calco, adaptación de todo lo extraño y de todo lo nuevo. Nuestro mundo no ha mucho tiempo era un mundo natural y en él podía vivirse sin embarazo (...), nuestras ideas y nuestras costumbres, producto y consecuencia de nuestra historia, regían nuestros movimientos y nos bastaban; con ellas era la libertad en la vida y con ellas la nitidez en los espíritus (...); sólo cuando los hechos ulteriores no fueron consecuencia de los precedentes comenzó nuestra desgracia (...). Nuestro mal (...) se halla en nuestra sumisión estúpida a todo lo nuevo" (Ibidem:327-328).

Las palabras de Arana revelaban una crítica a la civilización moderna y a la condena que en nombre de ésta se hacía a las prácticas comunitarias propias, acusadas de barbáricas y de obstáculos a la modernidad. Cabe decir, que este rechazo a las consecuencias de la modernidad se iría diluyendo poco a poco en 
el Partido Nacionalista Vasco (fundado por Arana en 1895), siendo la original doctrina de Arana objeto de disputas entre sus seguidores más integristas y los que deseaban un acomodo ideológico nacionalista a la inevitable sociedad moderna. Esta división tendrá su culminación en 1921, con la separación entre la aburguesada Comunión Nacionalista Vasca y el nuevo y más proletarizado PNV (que hizo suyo el semanario de la Juventud Vasca, Aberri, a cuyos mandos se encontraba Elias Gallastegi) (Beramendi, 2001: 282, Mees, 1990: 115-139).

\section{Antimodernidad e izquierda abertzale}

La victoria franquista sobre el conjunto de los territorios vascos supuso un reverdecimiento de aquella hecatombe para la identidad vasca observada por Arana en el ocaso del siglo XIX. Desde la interpretación crítica de la modernidad, el franquismo puede ser descrito como la mejor expresión del fascismo hispano y en concomitancia con la formación del nacionalsocialismo en Alemania y del fascismo en Italia. Como estos últimos, el franquismo encarnó la dualidad de un discurso ideológico enaltecedor del primitivismo (una apelación a la rebelión de lo natural) y una práctica sistematizada de la racionalidad del dominio. Casarían así en el franquismo, como en Italia y Alemania, una proyección pública que miraba al pasado tradicional y mítico (la monarquía hispánica y la religión como elementos cruciales de la gloria de la patria) y una fe inquebrantable en el progreso racional. La dualidad referida se representaría en el franquismo en la conjunción de dos familias políticas: la monárquico tradicionalista y la falangista.

En virtud de lo anterior, y a decir de Zira Box, el nacionalismo de la Falange vino profundamente atravesado por un hondo sentido proyectivo de la patria, "porque la clave ya no estaba en el ayer o en el pretérito (...), sino en la nación concebida como una unidad de propósitos mirando el porvenir" (Box 2013:906). En la misma línea, José Carlos Mainer advierte que

\footnotetext{
“cuando el inventor del fascismo español, Ernesto Giménez Caballero, propuso la reutilización global del nacionalismo liberal español, al modo que los fascistas italianos habían hecho con el pensamiento patriótico del Risorgimento, vino a descubrir dos cosas obvias: en primer lugar, que el fascismo formaba parte (...) de la modernidad" (Mainer 2013: 855).
}

Por su parte, el tradicionalismo elaboró su doctrina a partir de autores que iban desde Donoso Cortés, Aparisi y Guijarro a "Menéndez Pelayo, de quien se tomaba el papel esencial de la religión para la consecución de la unidad de España y su visión providencialista de la historia” (Box 2013:904). La mitificación de la España arcaica, medieval, pre-moderna del discurso tradicionalista, vino así a 
introducirse en el panegírico vitalista de la Falange, que había carecido hasta entonces del mito efervescente sobre el que soliviantar a las masas y posibilitar su revolución. Así, y tras el Decreto de Unificación, "un catolicismo fascistizado y un fascismo muy beato se coaligaron estrechamente bajo el conjuro del gran baño lustral de sangre" (Mainer 2015:230).

En esta línea, el nuevo régimen pondrá en pié un sistema que tratará de someter, apelando a las potencialidades de rebelión que ofrecía la llamada a la naturaleza, a los pensados desde la racionalidad instrumental como "pueblos primitivos" (Horkheimer 2010:137). Con el franquismo, en palabras de Gurrutxaga, se reproduce "la vieja aspiración hispana de estructurar un Estado nacional con suficientes dosis de legitimidad para crear una comunidad nacional y presentarse como evidencia social" (Gurrutxaga 1985: 160). El franquismo, pues, se constituiría como el colofón de los intentos por estructurar un Estado moderno tras los fracasos liberales y, consecuentemente, resultaría el paso requerido para la completa objetivación de la realidad social y del "carácter comunitario de la identidad de los habitantes sobre el territorio" (Pérez Agote 1984: 48). Habría que añadir, desde el punto de vista filosófico, que el nuevo Estado configura el panlogismo hegeliano consistente en la reducción de la realidad al Logos, reproduciendo una dialéctica sistemática expresada por el de Stuttgart en la Lógica y en la Filosofía del Derecho. A ello habría de contraponerle Adorno la Dialéctica Negativa, como crítica permanente al deseo abstraccionista a partir del cual se practica la reducción de la pluralidad sensible a la identidad ideal del concepto; la supresión de la diferencia y la imposición de lo idéntico (Berardi 2016:74; Reale y Antiseri 2005:739; Hernández Pacheco 1996:89).

"El genocidio -en palabras de Adorno- es la integración absoluta que se prepara en todas partes donde los hombres son nivelados, pulidos (...) hasta que, desviaciones del concepto de su perfecta nulidad, literalmente se los extermina" (Adorno 2005: 332).

De esta forma, y dentro de las propias familias del franquismo, se fundamentó una histórica paradoja: los tradicionalistas acabaron por ser participes, mediante su discurso y por sus armas, de un proyecto nacional, el falangista, que asumía uno de los puntales de la revolución moderna: la uniformización/ abstracción cultural y administrativa del Estado ${ }^{6}$.

\footnotetext{
6 Julio Aróstegui recordaba: "la creación de Estados de poder centralizado es la característica más peculiar del modelo de Estado nacional que deriva de las ideas revolucionarias" (Aróstegui 1998:31-57). Núñez-Seixas ha destacado a este respecto que si bien los falangistas aceptaban un pluri-folclorismo en la "nueva España", a fin de sustanciar la idea de Imperio, esta diversidad formal quedaba superada en la comprensión de una España unida en "la comunión de valores, la conciencia de su pasado histórico y su destino universal". Por el contrario, algunas facciones carlistas pensaron hasta 1937 que esta "nueva España", "se basaría sobre las autarquías regionales y alguna forma de 
El temprano fin de los Conciertos Económicos en Bizkaia y Gipuzkoa y la persecución a los rasgos comunitarios vascos se entroncaron en paralelo con el desarrollo, a partir de los años 50, de una masiva, descontrolada y nueva fase de industrialización. Ésta, si bien no se logró según los programas autárquicos de los falangistas (el milagro económico debía su éxito a la liberalización económica en un sentido netamente capitalista, concretamente a la política preestabilizadora de 1957, el Plan de Estabilización de 1959 y los planes de desarrollo a partir de 1964), alcanzó el tan pretendido anhelo de modernización nacional. Pero como señaló Viñas, "los luceros joseantonianos no [eran los que] iluminaban el futuro" (Viñas 2015: 85).

De una forma simplista, aunque cierta, John Sullivan señaló, a la hora explicar los orígenes de ETA, que "lo que salvó al nacionalismo vasco del estancamiento fue la recuperación de la economía española en los años cincuenta, lo cual produjo una invasión de maketos" (Sullivan ${ }^{1996}$ : 332). Gaizka Fernández y Raúl López Romo han indicado que la inmigración, consecuencia de esta reindustrialización, es vista desde el movimiento nacionalista, recluido en las esferas de la intimidad durante la dictadura, "como un problema que desnaturalizaba al País Vasco" (Fernández y López 2010: 193-217). Una desnaturalización ante la que habría que reaccionar.

Así pues, todo este proceso volvió a someter a los oriundos a las mismas contingencias existenciales que en época de Arana, caracterizando de nuevo el desarrollo de la modernidad como un proceso absolutamente disolvente. Este aspecto disolvente, relacionado inherentemente a la voluntad de totalización, ha sido definido por autores como el historiador y filósofo Xabier Irujo, y en recogimiento de las tesis de Raphael Lemkin (y en analogía con la filosofía de la no-identidad adorniana), como genocida (Irujo: 2015). La lógica de centralización de la soberanía unida a la nueva fase abierta del desarrollo capitalista, convino a exacerbar el estado ruinoso de los rasgos diferenciales vascos sometidos al progreso e, inversamente, motivó la prospección, desde el propio sufrimiento existencial de parte de los habitantes del territorio vasco, de nuevos arquitectos que reconstruyeran los restos.

La primera ETA surge en esta tesitura de aceleración de las contradicciones entre una fase nueva de industrialización que somete los rasgos diferenciales vascos y la supervivencia de esos mismos rasgos en las esferas de lo que Ander Gurrutxaga denominó "la sociedad del silencio". Una sociedad refugiada a estos espacios del silencio tras "haber decretado el régimen dominante el cierre del espacio público" (Gurrutxaga 1985: 422).

Si bien la primera ETA era una reacción de las nuevas generaciones nacionalistas del interior a las tesituras existenciales y a la inactividad de la

descentralización basada en el sufragio corporativo (...).En vano, el conde de Rodezno aún apelaba en septiembre de 1937 a la próxima «restauración foral»" (Núñez-Seixas 2014:135).

Araucaria. Revista Iberoamericana de Filosofia, Política, Humanidades y Relaciones Internacionales, año $22, \mathrm{n}^{\circ} 43$. Primer semestre de 2020. Pp. 119-142. ISSN 1575-6823 e-ISSN 2340-2199 https://dx.doi.org/10.12795/araucaria.2020.i43.06 
dirigencia del PNV del exterior, las condiciones económicas del conjunto de obreros en Euskadi dieron pie a la organización para trabajar un viraje ideológico que acabaría por romper los hilos que la unían con un aburguesado PNV. Un cierto desvío que en puridad, y al menos durante los comienzos de la organización, se concebía más como un proceso de destilación de las esencias nacionalistas (la recuperación del significado original de las palabras de Arana), las cuales como ya habían abordado grupos como Aberri, significaban la defensa de la patria vasca como vía para abordar la "cuestión social". Una cuestión que en el fondo permitiría concebir la realidad "maketa" desde puntos de vista sustancialmente menos xenófobos (y no racistas), comprendiendo a estos emigrados económicos no tanto como victimarios de una comunidad, sino como víctimas de una sociedad moderna. ETA, en el primer número de su boletín Zutik, señalaba:

\begin{abstract}
"Hay vascos que opinan que el único problema es el social. Opinan que nuestra lucha nacional es una monserga pasada de moda (...). Es curioso, como si quisiéramos ser libres para cantar zortzikos salpicados de irrintzis o tocar la alboka. Nuestro patriotismo es instrumental: queremos libertad para afrontar los problemas que tiene planteados Euzkadi y el mundo con solución comunitaria de pueblo. Creemos que Euzkadi contribuirá eficazmente a la solución del problema social"?.
\end{abstract}

Aun en esta primera época, la organización, en su primera publicación, el conocido como "Libro Blanco", decía cosas como que "la solución política de echar a los extranjeros es una utopía considerada, sobre todo, en sentido amplio", pero que "más importante nos parece la asimilación de quienes llevan algún tiempo en Euskadi"8. En el Zutik número 11 (abril de 1963), en uno de los varios artículos sobre la cuestión de la inmigración, se señalaba: "una cosa es el inmigrante, digno de todos nuestros respetos; y otra cosa es el chulapón que se cree en tierra de esclavos y que, a causa de ello, solo merece ser tratado como un agente extranjero". En el Zutik número 12 se concibió una evolución al respecto del problema de la inmigración. Ésta,

"no puede ser otra que una solución de integración total, sin reservas...una solución vasca (...). [La inmigración es] un fenómeno socioeconómico, y por tanto, no es una maniobra política (...) Los trabajadores españoles en nuestro país, al igual que el pueblo vasco en general, son por razones diferentes, ciertamente, las víctimas del desastre franquista (...) Se trata de eliminar una frontera que no está trazada en la geografía de nuestra patria vasca; pero que no por ello es menos real (...) En todos aquellos puntos donde conviven la comunidad vasca por su origen y esa otra comunidad; también vasca puesto que

\footnotetext{
"Zutik 1", 1961. Documentos Y: n¹, n. 101.

8 "Libro blanco", 1960. Documentos Y: nº 1, n.386.

9 “Zutik 11", 1963. Documentos Y: n², Hordago, n.341.
} 
en nuestra patria trabajan y crean sus hogares, formada por los trabajadores que han venido a convivir con nosotros"10.

El arranque del nuevo pensamiento abertzale que comenzará a desarrollar ETA viene en parte marcado por el trabajo teórico de Federico Krutwig. No obstante, la tendencia a la hermandad con la problemática social y, por ende, a la pretensión de inclusión de la inmigración viene afectada por la realidad de las huelgas obreras de principios de los años 60. En el comienzo de la obra fundamental de Krutwig, Vasconia (1962), al referirse al sentido de la propiedad en el vasco, el autor señala:

"la abolición de los Fueros vizcaínos trajo al Señorío la legislación española de minas, que concede la explotación de los yacimientos a quien los denuncia. De esta forma pasó a manos privadas la propiedad de las comunas vascas que fueron expoliadas de sus derechos por el ocupante español" (Krutwig 2006:75).

Así pues, el pasado es desvelado como un progreso no fructificado frente a un racionalismo económico, impuesto por una ley extraña que impone un trascurrir que evoca a la esclavitud (Ibidem:78-79). Las leyes foráneas así "no han de servir más que para justificar la expoliación material del pueblo oprimido" (Ibidem:72). Para Krutwig la Revolución Francesa, y el proceso histórico modernizante que abrió consigo, es un duro golpe asestado a la sociedad vasca,

"ya que ésta no significaba ningún progreso social en nuestra patria (...) No es de extrañar que, contra toda lógica aparente, la introducción de las ideas revolucionarias, que desde el punto de vista ideológico, significaban un progreso para los estados antiguos, en distinto fondo histórico como el del País Vasco, significasen la destrucción del sentimiento democrático y comunista del pueblo vasco (...). La Revolución Francesa no trajo ningún progreso a la tierra euskalduna" (Ibidem:82).

Sin embargo, el autor acepta esta circunstancia, asegurando que:

"no nos podemos oponer el al devenir histórico, aunque sí tenemos que ajustarnos a él con nuestra idiosincrasia nacional. No hay pues por qué considerar que la industrialización de Vizcaya fue un mal. Ha servido para que nuestra patria no se transforme en un desierto. Lo que no podemos tolerar es aquello contra lo que protestaba ya el fundador del nacionalismo vasco: 'todos sabemos que hoy el pobre es inhumanamente explotado y tratado como bestia por industriales y comerciantes, mineros y propietarios" "(Ibidem:81).

10 “Zutik 12”, 1963. Documentos Y: n², Hordago, n. 352-353. 
El modo de producción capitalista se convierte así en la verdadera circunstancia perniciosa de la modernidad, y su combate, en una posibilidad para retraer la imposición de ésta. En virtud de lo anterior, el rechazo a la Ilustración no lleva a Krutwig a sostener el mismo odio del fundador del nacionalismo a las consecuencias derivadas del desarrollo de ésta, la inmigración. Y así, advierte:

"El racismo político del nacionalismo vasco se fundaba en la ignorancia del propio concepto de 'qué es raza'. Mezclaban este concepto antropológico con un concepto lingüístico (...). Partiendo de este nacionalismo racista, se opusieron sus partidarios a la entrada de elementos extraños creyendo que éstos iban a desvirtuar al pueblo vasco (...) Al no tener otra barrera que la asimilación rechazada y la conservación de un cierto número de apellidos, se empecinaron en ésta, en lugar de realizar una Dinámica positiva que asimilase a los inmigrantes" (Ibidem:108-109).

La nacionalización del inmigrante, propuesta por Krutwig, pasaría porque éste respete y aprenda la cultura del indígena y se adhiera a la lucha frente aquellos que han derogado la libertad subjetiva derivada de la particularidad del territorio. En Vasconia, la instancia estatal no es observada en exclusiva como irradiadora de una modernidad vacua cuya aplicación levanta consecuencias indeseables para la comunidad vasca, sino que se caracteriza con una ocupación que somete represivamente al conjunto de los habitantes que habitan un espacio físico concreto. Del desquite de la ocupación se superpone la fundamentación de la soberanía propia; el retorno a la posibilidad de aplicar el remanente utópico liquidado. De ahí la prospección de Euskadi como colonia que hace Krutwig y el compromiso con la estrategia de guerra revolucionaria. Y de ahí también que se levante, teóricamente al menos, la "barrera previamente infranqueable que separaba a los nacionalistas de los inmigrantes. En adelante, la represión franquista se encargará del resto" (Jauréguiberry 1983:179). En herencia de estas tesis, se presenta, justo antes de la Cuarta Asamblea de ETA, el documento "La Insurrección en Euskadi”. Como explica Francisco Letamendia:

"ETA está recreando en este período los signos de identidad de una nueva comunidad socio-política en la familia del nacionalismo vasco; y los significantes de estos signos los encuentra al alcance de su mano a principios de los años 60 en los textos de los clásicos (...) de las guerras de liberación anticolonial del Tercer Mundo" (Letamendia 1994:288).

ETA, sin embargo, no necesita imaginarse en una realidad colonial, porque para ésta la modernidad expresada en la brutalidad de la dictadura evidenciaría la culminación histórica del aplastamiento del mundo moderno sobre el territorio vasco; la terminación del proceso de sometimiento al proceso civilizador en la configuración del Estado moderno. (Fanon 2004, Dussel, 1994). En otro 
sentido, ETA imagina una realidad colonial porque bajo la dictadura -tal y como ocurría en el proceso de colonización-, la experiencia comunitaria dada telúricamente en una parte del Estado, es arrasada violentamente en favor de la objetualización e instrumentalización de los sujetos que en dicho territorio habitan, a fin de capacitar la terminación de la modernización del propio Estado. ETA percibe que la dictadura, el sufrimiento que provoca, está facultando el proceso de composición de una nueva subjetividad que vendría marcada por el rechazo histórico a dos formulaciones del dominio dadas en el País Vasco y brutalizadas bajo el franquismo: el rechazo a la asimilación étnico-cultural y el rechazo a la explotación capitalista. Ambos rechazos se sostenían en ser contradicciones dentro y para el sistema de la dictadura. La cultura vasca y su defensa como vínculo diferencial, y el trabajador no subsumido a la categoría abstractiva de productor bajo la impronta nacional-sindicalista, se revelaban, así, como el nosotros subjetivo que no era reducible a la identidad ideal del concepto (Altamira 2006:266; Holloway S.f; Hernández Pacheco 1996:89). La asimilación del inmigrante aducida por Krutwig (aculturización) quedaba suplantada así por la dinámica social antirrepresiva asociada al territorio. La composición de esta nueva subjetividad fijaba un nosotros

\begin{abstract}
"al que cualquier habitante vasco, fuera cual fuera su origen social o étnico podía engancharse sin ninguna otra determinación que su voluntad y su subjetividad. Voluntad y subjetividad que deben buscarse (...) sobre todo, en este espacio público clandestino, cada vez más amplio que se encontraba gestándose en torno a una nueva oposición al franquismo" (Jauréguiberry 1983:247).
\end{abstract}

\title{
Y así, y como señaló Adorno:
}

\begin{abstract}
“el principio radical de identidad perpetúa el antagonismo mediante la represión de lo antagónico por parte de la razón que domina la naturaleza. Aquello que no tolera nada que no se iguale a él mismo se convierte en lo contrario de la reconciliación, que erróneamente cree constituir. El acto de violencia de la equiparación reproduce la contradicción que él erradica" (Adorno 2017:462).
\end{abstract}

ETA pues no hace más que recoger teóricamente este rechazo doble, esa notredad telúrica particularizada, cuando plantea en la V Asamblea que su lucha es contra las "enajenaciones" -culturales, económicas y socialesconsecuentes del imperialismo español y francés que afectan al conjunto del Pueblo Trabajador Vasco" ${ }^{11}$. Advierte a su vez que "en Euskal Herria la clase dominante [étnicamente vasca] ha utilizado el poder de los Estados español y francés para la defensa de sus intereses capitalistas y de ahí que sea objetivamente extranjera y opresora del Pueblo Vasco"12. La asunción de la

\footnotetext{
11 “Ideología oficial de Y”, 1967. Documentos Y: nº7, Hordago, n. 98-99.

12 Ibidem.
} 
categoría de Pueblo Trabajador Vasco (PTV) no hacía más que conceptualizar teóricamente la formación de la nueva subjetividad que, incluyendo ab origene a los inmigrantes ${ }^{13}$, señalaba para ETA el sujeto proyectivo de la conciencia nacional a partir de la cual retornar a la comunidad arrollada por la modernidad. En otro sentido, la subjetividad, formada en torno al rechazo a la represión, será el cimiento sobre el que construir un sujeto revolucionario (el PTV) a partir de la adopción de la conciencia nacional, lo cual significaba, a ojos de ETA, la lucha por la independencia (que liberaría esa nueva composición de lo vasco, como vasco y como explotado). Si el sufrimiento, su rechazo, la no-identidad, fijan un vínculo experiencial colectivo, sólo la vehiculación a través de la adquisición de la conciencia nacional capacitaría, en puridad, y para ETA, el salto revolucionario y la emancipación. En opinión de Francisco G. Aguirrezabala:

"la definición del Pueblo Vasco como sujeto revolucionario por ser expresión de un antagonismo histórico con los Estado de España y Francia, abre la posibilidad de utilizar dicho antagonismo para hacer prender la chispa que acelere la confrontación con el estado de cosas vigente y con las cosas de los estados vigentes y emergentes (...), transformando el conflicto vasco en un foco revolucionario para transformar la sociedad..." (Garmendia Aguirrezabala 2000:44).

La demanda por la supervivencia de la tradición comunitaria -arrasada por las mismas fuerzas que oprimen al trabajador- se definiría en lo sucesivo como una reivindicación emancipadora, reconstituyendo dicha tradición en el presente y como lugar desde donde extraer significantes para la motivación de

${ }^{13}$ Gaizka Fernández y Raul López han señalado a este respecto que "desde el nacionalismo vasco radical los discursos sobre la inmigración han hecho hincapié en los requisitos que habían de cumplir los inmigrantes para conseguir o no carta de vascos. Ello se solventó considerando que los vascos integrados eran los que se habían hecho nacionalistas". A mi juicio esta es una idea errónea, pues la nueva vinculación experiencial de la represión compone un nuevo sentido de lo vasco que es tan sólo recogida teóricamente por ETA cuando habla de Pueblo Trabajador Vasco. La integración no se realiza, en la propia lógica etarra, por la adopción de ninguna conciencia nacional, sino por la composición práctica de la subjetividad en la realidad social. En el proceso del rechazo anti-represivo, el inmigrante se sensibiliza de la persecución de lo vasco. El nacionalista percibe que la persecución de toda experiencia colectiva cultural, de todo aquello que la modernidad le ha hecho único defensor, es provocada por las mismas fuerzas que posibilitan la explotación capitalista. Los autores afirman que "la barrera del nacionalismo radical frente a los inmigrantes ya no era racial (...) sino ideológica". Pero, tal barrera ideológica -extranjerizante- era una barrera no puesta exactamente a los inmigrantes en cuanto a tal, sino a los miembros de esa subjetividad, inmigrantes o no, -y también, y sobre todo, a la gran burguesía vasca-, que no eran apercibidos por la conciencia nacional que ETA deseaba plantear como vehiculación del rechazo a la dictadura y al sistema capitalista. Si como dicen, acertadamente, "el nacionalismo radical actualizó las formas de exclusión racistas de Sabino Arana para emplear, esta vez un criterio ideológico de adscripción étnica", pervive en su planteamiento de discriminación a la inmigración una antinomia irresoluble, ya que si se aplica un criterio ideológico como vehículo de adscripción étnica esto comprometería su misma aplicabilidad al sentido diferencial con respecto a la inmigración; dicho de otra forma, también habría trabajadores vascos culturalmente (oriundos), que realmente, y siguiendo este criterio, no serían vascos porque no son nacionalistas. (Fernández y López 2010:193-217; Fernández y López 2018).

Araucaria. Revista Iberoamericana de Filosofia, Política, Humanidades y Relaciones Internacionales, año $22, \mathrm{n}^{\circ} 43$. Primer semestre de 2020. Pp. 119-142. ISSN 1575-6823 e-ISSN 2340-2199 https://dx.doi.org/10.12795/araucaria.2020.i43.06 
la lucha del sujeto revolucionario. La cultura vasca, el euskera especialmente, se constituye en la imagen dialéctica benjaminiana, en el remanente utópico liquidado, de una comunidad arcaica sin clases (Benjamin, 2004:39). Diría Tomás Goikoetxea:

\begin{abstract}
"En Euskadi, a la cultura latino-cristiana, se junta el imperialismo ideológico de la cultura de masas industrial; uniformadoras ambas, que ponen en peligro de desaparición, pura y simple a la cultura tradicional. Una lucha socialista nacional es definitivamente un combate por el renacimiento nacional (...) En el pueblo vasco (...) debe operarse una auténtica revolución cultural y sensible, de real transformación personal y colectiva, lejos del folklorismo y del culturalismo abstracto. Una transformación y reencuentro de su identidad nacional síntesis de lo tradicional y moderno, que le ayuden a combatir los elementos alienantes y represivos de la ideología cristiana o de la unidimensionalidad e individualismo industrial de masas" (Goikoetxea 1976:48).
\end{abstract}

\title{
Conclusión
}

A lo largo del presente escrito se ha tratado de observar no ya sólo una mimética proyección antimoderna entre las dos fases del nacionalismo referido (el iniciático y el reformado durante el franquismo), sino una profunda evolución del contenido de esta proyección, que a la postre redundó -desde el originario rechazo a la inmigración- en un proyecto potencialmente revolucionario a partir de la nueva composición subjetiva que incluía al conjunto de trabajadores habitantes en los territorios vascos. La conceptualización del Pueblo Trabajador Vasco realizada por ETA, recogía, así, la unificación de dos notredades sufrientes particularizadas en el territorio vasco bajo la dictadura.

Si el primer nacionalismo vasco se levanta como reacción a la eliminación práctica de la experiencia comunitaria, como rechazo a la reducción de la diversidad concomitante al sentido de modernización de la estructura del Estado y el desarrollo voraz de la industrialización, el nuevo nacionalismo vasco, la izquierda abertzale, surge como rechazo ante la totalización abstractiva realizada bajo el franquismo. Dicho de otra forma, surge de la misma eventualidad histórica que el primer nacionalismo, pero explora un acercamiento hacia la clase obrera, negada como tal en el reduccionismo social y teórico del franquismo. Este paso es fundamental pues revoca sustancialmente las primigenias formulaciones racistas, pero más importante aún: elimina la retórica del retraimiento histórico y la proyección eidética de lo vasco del nacionalismo primigenio. Esto no significa que no hubiera -y hayauna mitificación desbordante de la historia vasca previa a la intrusión de la modernidad en el Estado, pero el rechazo ya no se traduciría como lucha contra 
la pérdida del pretendido sentido del ser vasco -solución heideggeriana del primer nacionalismo y de la primera ETA-, sino como confrontación desde el todo aquello que no cabe; una lucha desde lo negativo en la realidad afirmada, configurándose así en una potencialidad revolucionaria.

\section{Referencias bibliográficas:}

Adorno 2005: T.Adorno, Dialéctica Negativa (Madrid, 2005).

Adorno 2017: T.Adorno, Ontología y Dialéctica. Lecciones sobre la filosofia de Heidegger (Buenos Aires,2017).

Altamira 2006: C.Altamira, Los marxismos de fin de siglo (Buenos Aires, 2006).

Arana 1999: S.Arana, Antología de Sabino Arana (Donostia,1999).

Aranzadi 1981:J.Aranzadi, Milenarismo vasco. Edad de oro, etnia y nativismo (Madrid,1981).

Aróstegui 1998: J.Aróstegui, "El Estado español contemporáneo: centralismo, inarticulación y nacionalismo". Historia Contemporánea, No . 17, n.31-57.

Benjamin 2004: W.Benjamin, Libro de los pasajes (Madrid, 2004).

Beramendi 2001: J.Beramendi "Regionalismos y nacionalismos en España".

En M. Ortiz, D.Ruiz y I.Sánchez, Movimientos sociales y Estado en la

España Contemporánea (Cuenca, 2001), n. 265-296.

Berardi 2016: F.Berardi, Almas al trabajo (Madrid, 2016).

Box 2013: Z.Box, "El nacionalismo durante el franquismo". En: A. Morales

Moya, J.P. Fusi y A. De Blas Guerrero, (Dir.), Historia de la nación y del nacionalismo español (Barcelona, 2013), n.903-920.

Castells 2009: L.Castells, "El nuevo marco administrativo y la autonomía (1876-1923)". En: L. Castells y A. Cajal, (Eds), La autonomía vasca en la España contemporánea (1808-2008) (Madrid, 2009), n. 107-157.

Castells 2007: L.Castells, "Liberales, fueros e identidades en el País Vasco (1850-1919). En: L.Castells, A.Cajal y F.Molina (Eds.), El País Vasco y España: Identidades, Nacionalismos y Estado (siglos XIX y XX) (Bilbao, 2007), n.115-161.

Corcuera 1980: J.Corcuera, Orígenes, ideología y organización del nacionalismo vasco (1876-1904) (Madrid, 1980).

Cortina 2008: A.Cortina, La escuela de Fráncfort: crítica y utopía (Madrid, 2008).

Díez Medrano 1999: J. Díez Medrano, Naciones divididas. Clase, política y nacionalismo en el País Vasco y Cataluña (Madrid 1999).

Dusell 1994: E.Dusell, 1492. El encubrimiento del otro (La Paz, 1994).

Elorza 1978: A.Elorza, Ideologías del nacionalismo vasco (Zarautz, 1978). 
Elorza 1977: A.Elorza, "El tema rural en los orígenes literarios del nacionalismo vasco". En: Actas del Quinto Congreso de la Asociación Internacional de Hispanistas : Bordeaux, 2-8 de septiembre de 1974 (Burdeos, 1977) n. 355-376. Fanon 2004: F.Fanon, Los condenados de la tierra (Tafalla, 2004).

Fernández y López 2010: G.Fernández y R. López, “Enemigos internos o nuevos aliados? Los inmigrantes y el nacionalismo vasco radical (19591979)". Alcores, $\mathrm{N}^{\mathbf{0}}$.10, n. 193-217.

Fernández y López 2018: G.Fernández y R. López, "From ethnic exclusión to terrorism? The case of Basque nationalism". Journal of Iberian and Latin American Studies, V.24, n. 443-459.

Fernández Sebastián 1993: J.Fernández Sebastián, “Antecedentes, fuerismo, carlismo, nacionalismo". En: S. De Pablo, S. (Ed.), Los nacionalistas. Historia del nacionalismo (1876-1960) (Gasteiz, 1993), n.17-51.

Fernández Sebastián 1990: J.Fernández Sebastián, "Ideología, Fueros y Modernización. La Metamorfosis del Fuerismo. 1: Hasta el Siglo XIX". Historia Contemporánea, N. 4, n. 61-88.

Garmendia Aguirrezabala, 2000: F.Garmendia Aguirrezabala, "La actual situación vasca". En: J.Elzo, y G.Bizcarrondo, (Ed.), La convivencia en la sociedad vasca. Los puentes de Deusto. Actas de un debate universitario (Bilbao, 2000), n. 21-108.

Goikoetxea 1976: T.Goikoetxea, Sobre nacionalismo revolucionario, socialismo abertzale y marxismo nacional vasco (Hendaia, 1976)

Gurrutxaga 2002: A.Gurrutxaga, La Mirada difusa. Dilemas del nacionalismo (Irún, 2002).

Gurrutxaga 1985: A.Gurrutxaga, El código nacionalista vasco (Barcelona, 1985).

Hernández Pacheco 1996: J.Hernández Pacheco, Corrientes actuales filosofía. La escuela de Fráncfort. La filosofía hermenéutica (Madrid, 1996).

Horkheimer y Adorno 2016: M.Horkheimer y T. Adorno, La dialéctica de la Ilustración (Madrid, 2016).

Horkheimer 2010: M.Horkheimer, Crítica de la razón instrumental (Madrid, 2010).

Holloway, S.f.: J.Holloway, “¿Por qué Adorno?”. En Herramienta. Revista de debate y crítica marxista. En: $<$ https://www.herramienta.com.ar/articulo.php?id=291> Irujo 2015: X.Irujo,Genocidio en Euskal Herria. 1936-1945 (Iruñea, 2015).

Jaúregui 1998: G.Jaúregi,En torno al hecho y la cuestión nacional (Madrid, 1998).

Jauréguiberry 1983: F.Jauréguiberry, Question nationale et mouvements sociaux en Pays Basque (Tesis) (Paris, 1983).

Jauréguiberry 2007: F.Jauréguiberry, Question nationale et mouvements sociaux en Pays Basque (Paris, 2007). 
Krutwig 2006: F.Krutwig, Vasconia (Navarra, 2006).

Lefebvre 1972: H.Lefebvre, Manifiesto diferencialista (México 1972).

Letamendia 1994: F.Letamendia, Historia del Nacionalismo y de ETA (Tomo 1)

(San Sebastián, 1994).

Luengo Texeidor 2009: F.Luengo Texeidor, "Restauración: identidad, fueros y autonomía. Liberales, republicanos y carlistas en la construcción de la identidad vasca (1876-1923)". En: L. Castells y A. Cajal, (Eds), La autonomía vasca en la España contemporánea (1808-2008) (Madrid, 2009), n. 135-157.

Mainer 2013: J.C. Mainer, "La imagen de Castilla en el fascismo español". En: A. Morales Moya, J.P. Fusi, y A. De Blas Guerrero (Dir.), Historia de la nación y del nacionalismo español (Barcelona, 2013), n. 855-873.

Mainer 2015: J.C.Mainer, "Letras e ideas bajo (y contra) el franquismo". En: J. Casanova (Ed.), Cuarenta años con Franco (Barcelona, 2015), n. 229-266.

Mees, 1990: L.Mees, “El nacionalismo vasco entre 1903 y 1923”. Vasconia, $\mathrm{N}^{\mathbf{0}} .17, \mathrm{n} .115-139$.

Mees 1996: L.Mees, "El nacionalismo vasco y España: reflexiones en torno a un largo desencuentro". Espacio, Tiempo y Forma, Serie V, No.9, n.67-83.

Mees 1991: L.Mees, Entre nación y clase (Bilbao, 1991).

Mees 2018: L. Mees, "Ethnogenesis in the Pyrenees: The Contentious Making of a National Identity in the Basque Country (1643-2017)". European History Quarterly, N.3, n. 462-489.

Mees 1992: L.Mees, Nacionalismo vasco, movimiento obrero y cuestión social (Bilbao, 1992).

Molina 2005: F.Molina, La tierra del martirio español. El País Vasco y España en el siglo del nacionalismo (Madrid, 2005).

Nahuel Martín 2016: F.Nahuel Martín, "Valencias de la dialéctica negativa. Totalidad antagónica y posibilidad de emancipación sin totalidad". Revista de Filosofia, N.2, n. 187-210.

Novia Salcedo 1851: P.Novia Salcedo, Defesa histórica, legislativa y económica del Señorío de Vizcaya y provincias de Álava y Guipúzcoa, (Tomo I) (Bilbao, 1851).

Núñez-Seixas 2014: X.M.Núñez-Seixas "La región y lo local en el primer franquismo”. En: Michonneau S. y X.M. Núñez-Seixas, Imaginarios y representaciones de España durante el franquismo (Madrid,2014), n.127154.

Núñez-Seixas 2018: X.M.Núñez-Seixas, Suspiros de España. El nacionalismo español 1808-2018 (Barcelona, 2018).

Pérez Agote 1984: A.Pérez Agote, La reproducción del nacionalismo. El caso vasco (Madrid, 1984).

Pérez Agote 2008: A.Pérez Agote, Las raices sociales del nacionalismo vasco (Madrid, 2008). 
Portillo 2018: J.M.Portillo, Entre tiros e historia. La constitución de la autonomía vasca (1976-1979) (Barcelona, 2018).

Reale y Antiseri 2005: G.Reale y D.Antiseri, Historia del Pensamiento Filosófico y Científico. Del Romanticismo hasta hoy (Barcelona,2005).

Rubio 1996: C.Rubio, Revolución y tradición. El País Vasco ante la Revolución liberal y la construcción del Estado español, 1808-1868 (Madrid,1996).

Smith 2000: A.Smith, Nacionalismo y modernidad: un estudio critico de las teorias recientes sobre naciones y nacionalismo (Madrid, 2000).

Solozabal 1974: J.J.Solozabal, El Primer nacionalismo vasco (Madrid, 1974).

Sullivan 1986: J.Sullivan, El nacionalismo vasco radical, 1959-1986 (Madrid, 1986).

Viñas 2015: A.Viñas, “Años de gloria, años de sombra, tiempos de crisis”. En: Casanova, J. (Ed.), Cuarenta años con Franco, (Barcelona, 2015) n. 79114.

Wellmer 1993: A.Wellmer, Sobre la dialéctica de modernidad y posmodernidad (Madrid, 1993).

Zelik 2017: R.Zelik, La izquierda abertzale acertó (Tafalla, 2017).

Žižek 2008: S. Žižek, En defensa de la intolerancia (Madrid, 2008). 